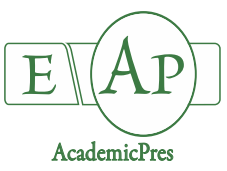

Beyaz A and Ozkaya MT (2021)

Notulae Botanicae Horti Agrobotanici Cluj-Napoca

Volume 49, Issue 1, Article number 12139

DOI: $10.15835 /$ nbha49112139

Research Article

\title{
Canopy analysis and thermographic abnormalities determination possibilities of olive trees by using data mining algorithms
}

\author{
Abdullah BEYAZ ${ }^{1 *}$, Mücahit Taha ÖZKAYA ${ }^{2}$ \\ ${ }^{I}$ Ankara University, Faculty of Agriculture, Department of Agricultural Machinery and Technologies Engineering, 06130, \\ Aydınlıkevler, Ankara,Turkey; abeyaz@ankara.edu.tr ( ${ }^{*}$ corresponding author) \\ ${ }^{2}$ Ankara University, Faculty of Agriculture, Department of Horticulture, 06130, Aydinlıkevler, Ankara, \\ Turkey;ozkaya@agriankara.edu.tr
}

\begin{abstract}
In order to take the appropriate tree protection measures, it is crucial to determine and track abnormalities that may occur in olive trees in time to time for many reasons. Abnormalities start in different sections of the trees, depending on the environmental effects of the olive tree, with a specific impact like fungal diseases, drought, etc. after a certain age especially in non-resistant species. Protection steps may be taken when abnormalities are apparent or predictable in certain olive trees, using some external indicators. However, when abnormalities formed within trees cannot be identified externally, there is a sudden breakdown and overthrow of valuable properties, such as monument trees. In the literature, various devices and methods are explained to classify these defects in different trees. By the way, in this research, a non-destructive inspection method (thermography) was clarified and used to assess anomalies in old olive trees without damage in the interior. According to the results of average thermal data, 60, 400, 600 years-old olive trees, 60-40, 70-30 and 80-20 learning-prediction data rates decision tree and random forest results according to normal and abnormal thermal difference, the thermal range was found as $35.95^{\circ} \mathrm{C}$ at 60 years-old tree, also it was found as $36.25^{\circ} \mathrm{C}$ at 400 years-old tree and it was found as $38.25^{\circ} \mathrm{C}$ at 600 years-old tree.
\end{abstract}

Keywords: abnormality; canopy volume; data mining; image analysis; olive tree; thermography

\section{Introduction}

The inspection of the health condition of old trees, especially of those growing in the villages potentially causing a great risk, and their property is required from time to time (Kubus, 2009). Especially, in some olive trees, particularly in assortments of old and non-resistant cultivars, with the impact of parasitic sicknesses, and so on for a specific period, abnormalities start in the external and internal pieces of the trees, and sooner or later, harmed regions appear in the trunk. Because of these abnormalities, harmed regions debilitate the trees and irreversible results happen, for example, breaking and tipping in trees with the impact of environmental events. At the point when abnormalities start in olive trees are noticeable, protection measures can be taken, (for example, filling them with some strong substances like concrete, and supporting them with certain materials externally). Notwithstanding, when abnormalities start can't be seen externally, these measures can't be taken. It is imperative to decide the deformities in the inside of the old olive trees without harming the tree,

Received: 30 Oct 2020. Received in revised form: 06 Dec 2020. Accepted: 15 Jan 2020. Published online: 21 Jan 2021.

From Volume 49, Issue 1, 2021, Notulae Botanicae Horti Agrobotanici Cluj-Napoca journal will use article numbers in place of the traditional method of continuous pagination through the volume. The journal will continue to appear quarterly, as before, with four annual numbers. 
to secure these trees by taking the fundamental protection measures, and to limit the multifaceted harm brought about by the unexpected break. Indeed, numerous techniques have been utilized from the past to the present (Catena, 2003).

Hitting the tree trunk with a mallet, and so on and commenting as indicated by the sound that comes out, is the most straightforward, most established, and broad application used in this issue. The most important point for making the right remarks, in any situation, is that the person who conducts this procedure is an experienced individual. In addition, clarify that one of the least difficult applications is to evaluate and select visual signs in trees that incorporate the growth organs of conception (decay, not only in the part where the reproducing organ is seen, but in a wide area here and there in the tree), shading changes, splits, wide shell misfortunes, and pruned branches, leaves, hand check, and shading, etc. The other straight forward strategy taking pens from the tree with a steady drill. By thusly, it is conceivable to get a visual thought of the deformities present at the stature of the addition pen taken from the tree. It is likewise conceivable to gauge the impacts of development on gradual things (with the assistance of exceptional hardware, for example, thickness, loss of obstruction, and so forth) (Mattheck and Breloer, 1994).

In any case, the propelled techniques expressed in the literature are radiography (Habermehl and Ridder, 1995), thermograph (Catena et al., 1990; Catena, 2003; Catena and Catena, 2008), shigometer, rot distinguishing drill, resistograph, small scale drills (Dolwin, 1996) and gadgets that empower sound waves to examine (Bethge et al., 1996; Sandoz,1999; Deflorio et al., 2008).

Depending on these techniques, different gadgets have been assembled based on the essential standards (1-Gadgets measuring electrical conductivity, 2-Gadgets measuring drilling resistance, 3-Gadgets inspecting sound waves (single effect sonic and ultrasonic), 4-Gadgets using augmentation pen tests, and 5-Automated tomography gadgets).

A few gadgets enable more surveys and forecasts than basic speculative applications, but the cost of them is higher, and audits take longer, for the most part. Truth be told, more than one administrator is necessary for certain applications. Besides, these tools, by and large, should be located close to the tree, and open holes inside the tree, regardless of whether it is $2-3 \mathrm{~mm}$, for a portion of the strategies. A risk to the earth and human wellbeing is consistently present in instruments estimating radiographic $\mathrm{x}$-beams.

The infrared thermography strategy for a non-dangerous assessment of olive trees is underlined today, in contrast to these techniques. Infrared thermography depends on the $1800 \mathrm{~s}$ as a starting point. Warm radiation was discovered by English physicist William Herschel. Thermography has become a useful approach because of the efficient work of numerous analysts dealing with this subject (Macedonio Melloni, Gustav Kirchhoff, James Representative Maxwell, Joseph Stefan, Ludwig Boltzmann, Max Planck). This procedure can be utilized as an option in contrast to different techniques utilized in deciding variations from the norm in the inside parts in planted trees (Catena, 2003).

In this study, a non-destructive examination method (thermography) that allows the determination of abnormalities in the interior parts without any destruction in the old olive trees was explained and used to determine defects in old olive trees.

\section{Materials and Methods}

\section{Materials}

The geographical origin of the 'Kilis Yağlık' olive cultivar (Olea europaea L. cvs. 'Kilis Yağlık') is Kilis province, Turkey. 'Kilis Yağllk' is one of the most common olive cultivated in the Southeast Anatolia Region of Turkey and represents around 52\% of the growing areaarea of the SE Anatolia region. 'Kilis Yağlık' cultivar has good plantation characteristics adapted well to the environmental conditions of the South-eastern region of Turkey. 'Kilis Yağllk' has a high yield of fruits although shows alternate bearing. It is characterized by 
medium vigour, self-incompatibility, resistant to drought, medium-sized fruit, high productivity, and alternate bearing. Fruits are generally used in olive oil extraction.

The olive trees evaluated by the thermographic method consist of 60-years-old 18 trees, 400 -years-old 21 trees, 600 years-old 50 trees in order to see the differences between the olive trees which has different ages, planted in the gardens located in Kuru Kastel area of Kilis province, located at 36.696004"-37.075317" latitude and longitude values and an altitude of 688 meters above sea level. The region's GPS information is determined by ultra GPS Logger software used via an android mobile phone. Figure 1 shows this software that contains GPS information.

Figure 1. Ultra GPS Logger software interface

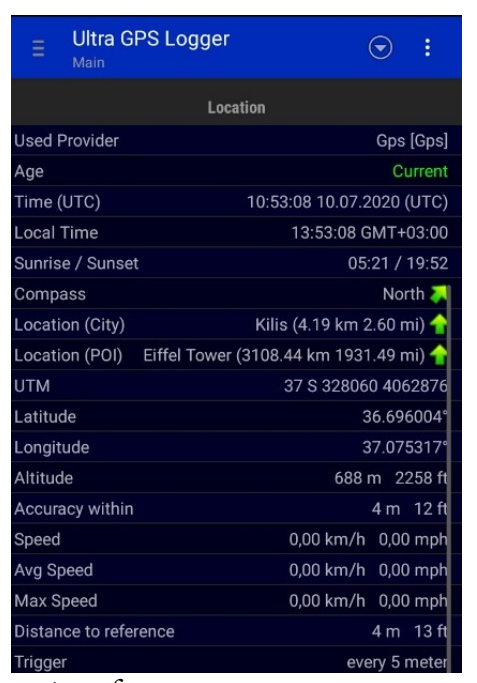

\section{Methods}

The thermographic measurement method was examined under two stages in the study. In the first stage, the working principle of the method of thermography has been explained, and then in the second stage, the issue of implementation on old olive trees has been mentioned.

\section{Thermography}

Thermography is a non-contact and non-damaging test strategy. It is conceivable to find out about the warm structure of an item up to a restricted depth with a solitary warm camera in this strategy. Thermography is a technique that allows moderately fast working in enormous territories, in contrast to other non-damaging assessment strategies. Also, thermography is used with this component for quality control purposes in the industrial zone. Infrared energy (IR) is a type of electromagnetic vitality, for example, radio waves, $x$-beams, noticeable light. All types of electromagnetic radiation proceed onward a level line and in waves. The distinction between them is that frequencies are extraordinary. IR's frequency can't be seen by the natural eye since it is excessively long (roughly 2-14 im). Because of environmental retention, the transmission of IR using air (transmission) happens on two frequencies: short (2-6 im) and long (8-14 |im). In contrast to noticeable light, IR likewise radiates infrared vitality on everything above total zero temperatures, even freezing objects (for example ice cubes). The higher the temperature of the item, the higher the IR radiation. To put it plainly, IR is a method that permits us to perceive what we can't see with the natural eye (Roth et al., 1997). The measure of vitality radiated from a surface relies upon certain variables and is communicated by the StefanBoltzmann equation.

$$
\begin{aligned}
& \mathrm{Q}=\mathrm{o}^{*} \mathrm{e}^{*} \mathrm{~T} 4 \\
& \mathrm{Q}=\text { Energy transferred by the glow } \\
& \mathrm{o}=\text { Stefan-Boltzmann constant }\left(0,1714^{*} 10^{-8} \mathrm{Btu} / \mathrm{hr}^{*} \mathrm{ft}^{2 * o} \mathrm{R}^{4}\right)
\end{aligned}
$$


$\mathrm{C}=$ Emissivity value of the surface

Dependent on Stefan Boltzmann's law, IR cameras were created. The IR camera's-controlled vitality is based on the emissivity coefficient (the coefficient of producing long frequency radiation). In all thermographic considerations, this coefficient is the principal constraining variable. To have a high coefficient $(\mathrm{C}>0.50)$, repeatable, accurate estimates are required.

\section{Olive tree volume measurement and computation}

Three different age groups of olive trees have been used for the canopy measurements. The measured dimensions of the tree canopies which had been used on Albrigo's Prolate Spheroid formula can be seen in Figure 2.

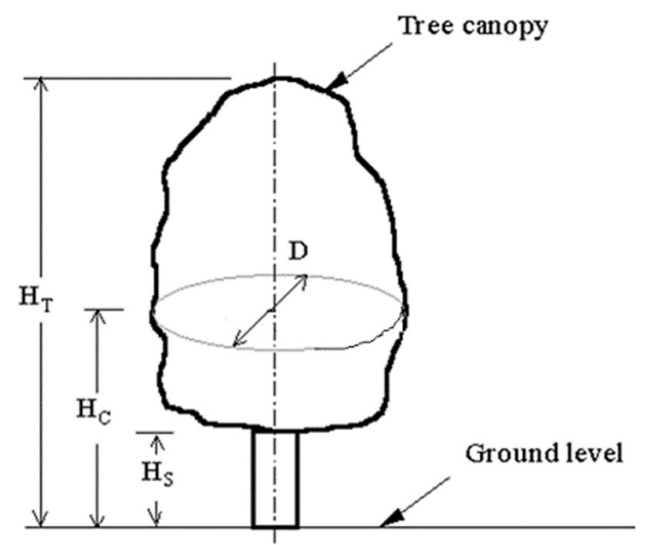

Figure 2. The dimensions that are used to compute canopy volumes in Albrigo's Prolate Spheroid formula

Measurements have been taken from image measurements with the help of a $1.5 \mathrm{~m}$ metal bar for the calibration. These measured values, then placed in Albrigo's Prolate Spheroid formula (1), and canopy volumes of each tree has been calculated by using this formula. The computer used in the study has a 27-inch monitor, Pentium i7, 4 GHz processor, 8 GB RAM, and ATI Radeon Rx560 graphic card.

$$
P S_{C V}=\frac{\pi \cdot D^{2}}{4} \cdot\left(\frac{2\left(H_{T}-H_{C}\right)}{3}+\left(H_{C}-H_{S}\right)\right) \quad \text { Albrigo et al. }(1975)
$$

Where;

$\mathrm{PS}_{\mathrm{CV}}=$ Canopy volume $\left(\mathrm{m}^{3}\right)$,

$\mathrm{H}_{\mathrm{T}}=$ Overall canopy height above ground level $(\mathrm{m})$,

$\mathrm{D}_{1}=$ Canopy diameter parallel to the row $(\mathrm{m})$,

$\mathrm{H}_{\mathrm{C}}=$ Height to the point of maximum canopy diameter $(\mathrm{m})$,

$\mathrm{H}_{S}=$ Height from ground to canopy skirt $(\mathrm{m})$

Canopy measurement parameters $\left(\mathrm{H}_{\mathrm{T}}, \mathrm{D}_{1}, \mathrm{H}_{\mathrm{C}}, \mathrm{H}_{\mathrm{S}}\right.$ specified in Figure 2$)$ of the olive trees measured and placed in Albrigo's Prolate Spheroid formula, then tree canopy volumes $\left(\mathrm{PS}_{\mathrm{CV}}\right)$ were calculated and stored.

\section{Image analysis measurements of olive trees}

The images have been captured with a Samsung Galaxy S9+ cell phone. The width and height values of images are set as $4032 \times 3024$ pixels. Captured images were evaluated by Myriad (v7) image processing software. This program has two steps for measurement. The first step is the calibration test of the program. For this purpose, the software needed a calibration ruler or a calibration plate. So, a graph paper was used for the first test of the software (Figure 3). 


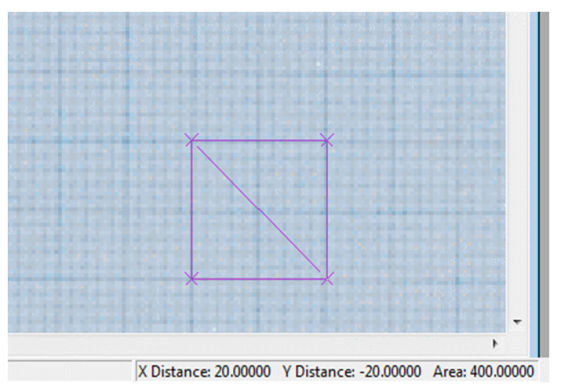

Figure 3. Graph paper test of image processing software

The second step is the selection of images and the measurement. A bar $(1.5 \mathrm{~m})$ has been used as a reference for the calibration of digital images (Figure 4).

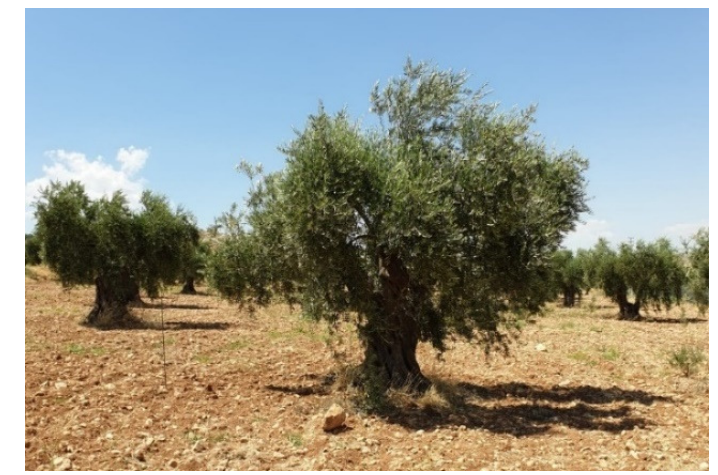

Figure 4. Calibration system sample of digital images for measurement of olive trees

The dimensions have been evaluated after the calibration of images (Figure 5). Myriad (v7) image analysis software used for obtaining canopy parameters from the olive trees $\left(\mathrm{H}_{\mathrm{T}}, \mathrm{D}_{1}, \mathrm{H}_{\mathrm{C}}, \mathrm{H}_{\mathrm{S}}\right.$ specified in Figure 2). Measured values were placed in Albrigo's Prolate Spheroid formula, then tree canopy volumes ( $\left.\mathrm{PS}_{\mathrm{CV}}\right)$ were calculated by using these parameters.

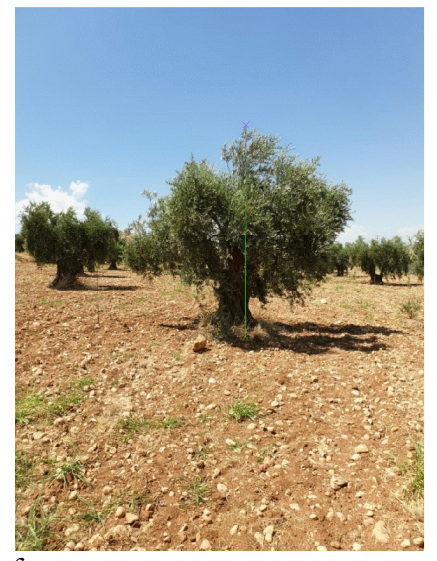

Figure 5. Myriad 8 image processing software 


\section{Use of thermography in olive trees}

The use of thermography is limited but highly successful in the studies on determining formations of decay, repellent, etc. in the interior of the monumental trees (Catena et al., 1990; Catena, 2003; Catena and Catena, 2008). Differences in the thermal characteristics (thermal conductivity and capacity) of inland cavities and cavity-free areas, decay, and solid tissues (thermal conductivity and capacity) have differences in the temperature of their surfaces.

In this research, TESTO 871 thermal camera was used to determine the abnormalities whether the olive trees in the region of Kuru Kastel in Kilis were in any danger as of their location, on 10/07/2020 (Figure 6).
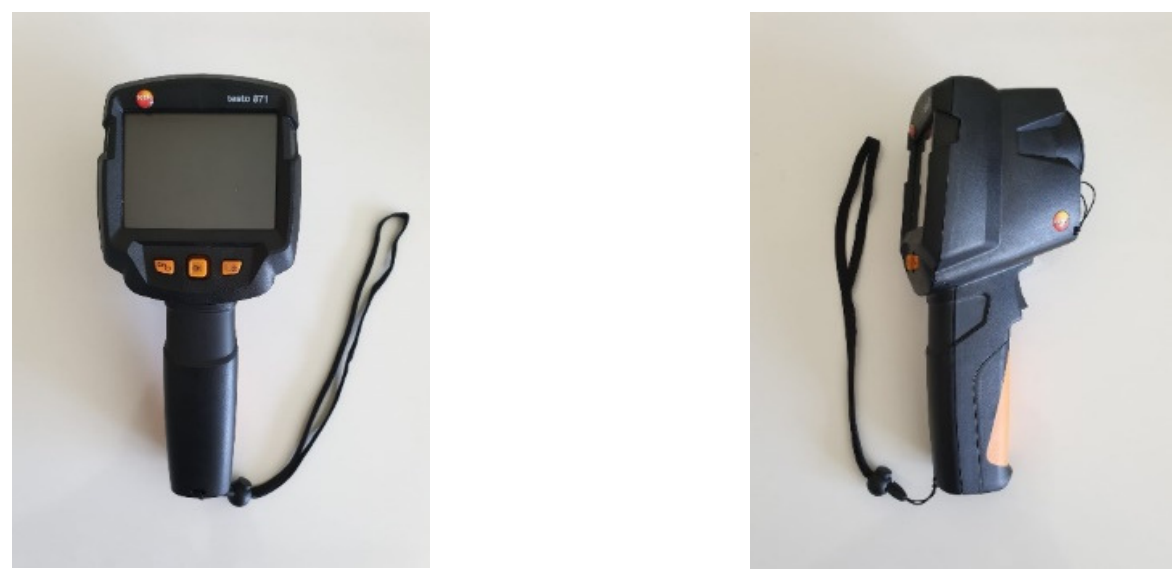

Figure 6. Testo 871 thermal camera

Specifications for Testo 871 thermal camera can be seen in Table 1. Testo 871 thermal camera is a mobile and effective thermal camera for this kind of measurement in olive tree orchards with its high-resolution thermal images.

Table 1. Specifications of the Testo 871 thermal camera

\begin{tabular}{|c|c|}
\hline \multicolumn{2}{|c|}{ Infrared image output } \\
\hline Focus & Fixed-focus \\
\hline Infrared resolution & $240 \times 180$ pixel \\
\hline Image refresh rate & $1.6 \mathrm{mrad}$ \\
\hline Super Resolution (IFOV) & $480 \times 360$ pixel \\
\hline Super Resolution (Piksel) & $2.6 \mathrm{mrad}$ \\
\hline Geometric resolution (IFOV) & $<0.5 \mathrm{~m}$ \\
\hline Min. focal distance & $35^{\circ} \times 26^{\circ}$ \\
\hline Field of view & $90 \mathrm{mK}$ \\
\hline Thermal sensitivity & $7.5 \ldots 14 \mu \mathrm{m}$ \\
\hline Spectral range & \\
\hline
\end{tabular}

According to the literature, images can be taken from the trees up to 20-25 m (Catena et al., 1990). Because of this reason, the nearby images were taken from 10 meters from the olive trees. The average temperature was $39.5^{\circ} \mathrm{C}$ during the time of the imaging process, relative humidity was $25.8 \%$ and the wind speed was $1.4 \mathrm{~m} / \mathrm{s}$ (Figure 7 ). 

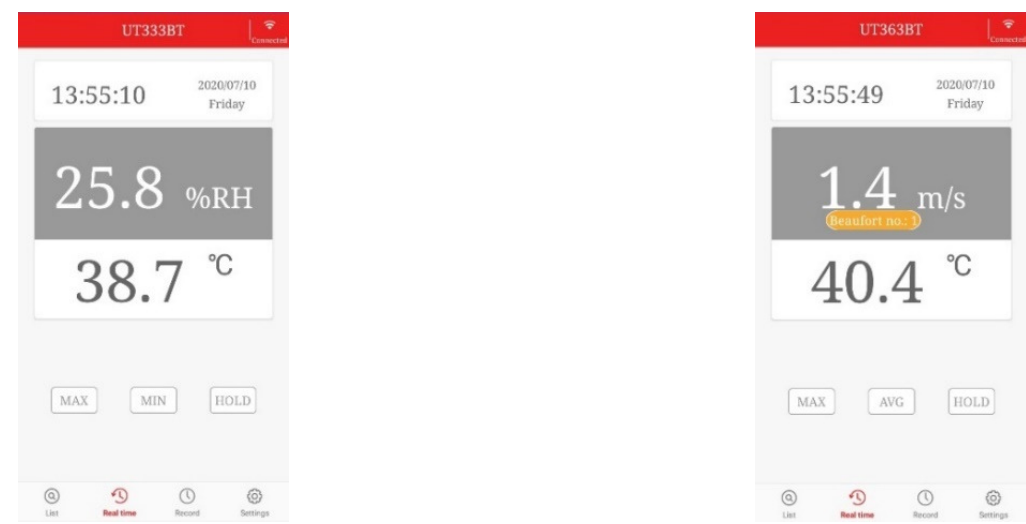

Figure 7. Measurement results of UT333BT temperature and humidity measurement (a), UT363BT wind speed measurement $(\mathrm{b})$ devices

On the contrary of some studies carried out before on this subject, the images were taken by not cutting down trees. Because the trees examined in this study have historical and cultural significance. Therefore, thermal images of the old olive trees were used for the evaluations and it is measured that the warm areas on the image (red, orange, and yellow are hot; green, blue, and blue show cold areas) indicate abnormalities based on the previous studies (Figure 8).

Although the studies on the use of this method in determining formations such as decay, repellent, etc. in the interior of various trees are quite limited, successful results have been obtained in these studies (Catena et al., 1990; Catena, 1991; Catena, 1992; Catena, 2003).

The general recommended method is briefly based on the determination of images of abnormalities in trees with an infrared camera (Figure 7). The fact that normal areas in these images will also cause changes in surface temperature due to differences between the thermal characteristics (thermal conductivity and capacity) of abnormal and robust tissues. If the thermographic image obtained from these differences is colored, it is defined in different colors according to the solid texture around the parts of the abnormality (Figure 8).

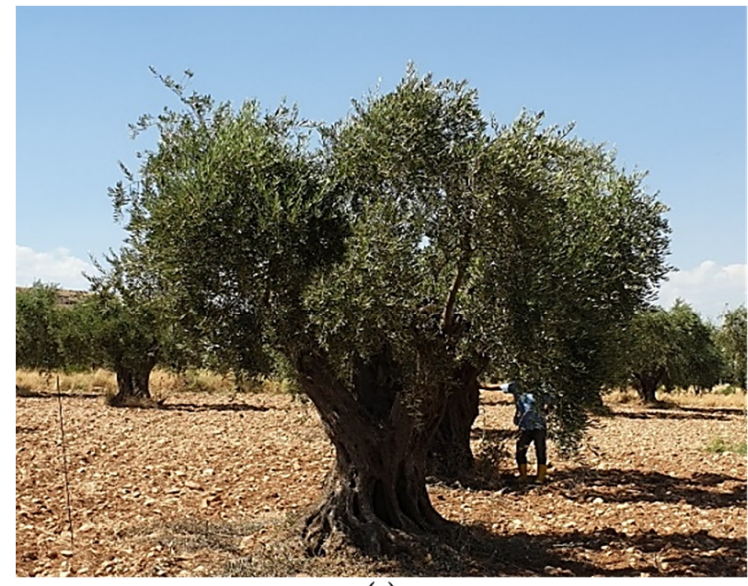

(a)

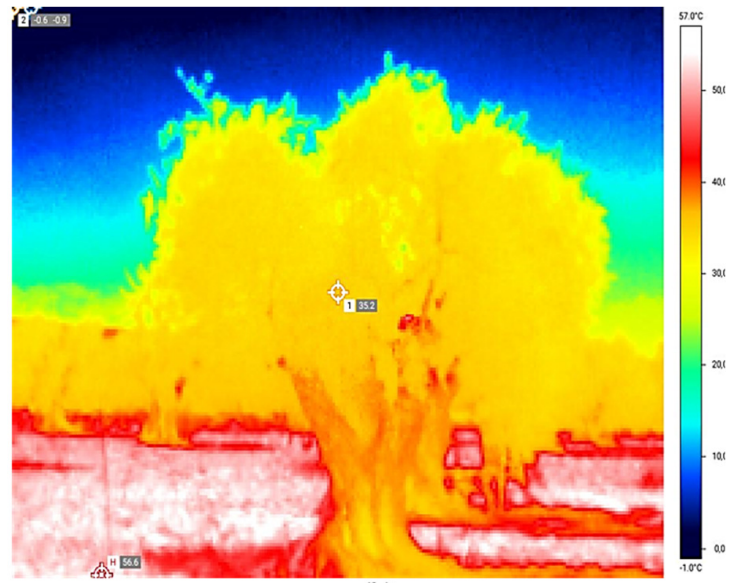

(b)

Figure 8. RGB (a) and thermal image from the old olive tree (b)

From the thermal images of olive trees whole olive tree temperature (TT), isotherm temperature of the olive tree (TI), and abnormality area temperature (TA) measurements were done by using Testo IRSoft. First, for the best edge detection of olive trees grayscale color palette was used for measurements (Figure 9). 


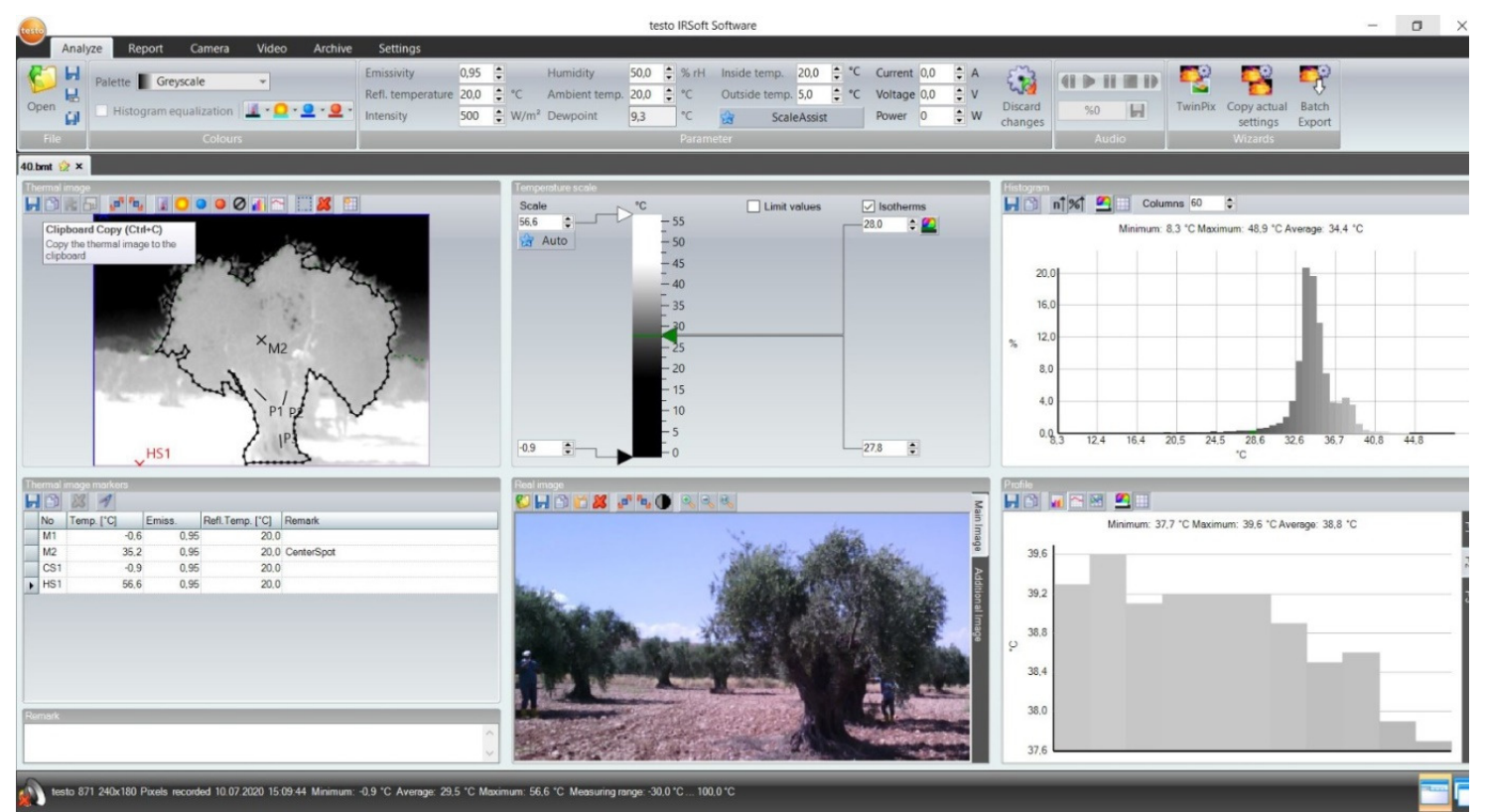

Figure 9. Grayscale olive tree thermal image analysis process with Testo IRSoft for the correct tree edge detection

Then, for the best thermal detection of olive trees rainbow color palette was used for measurements (Figure10).

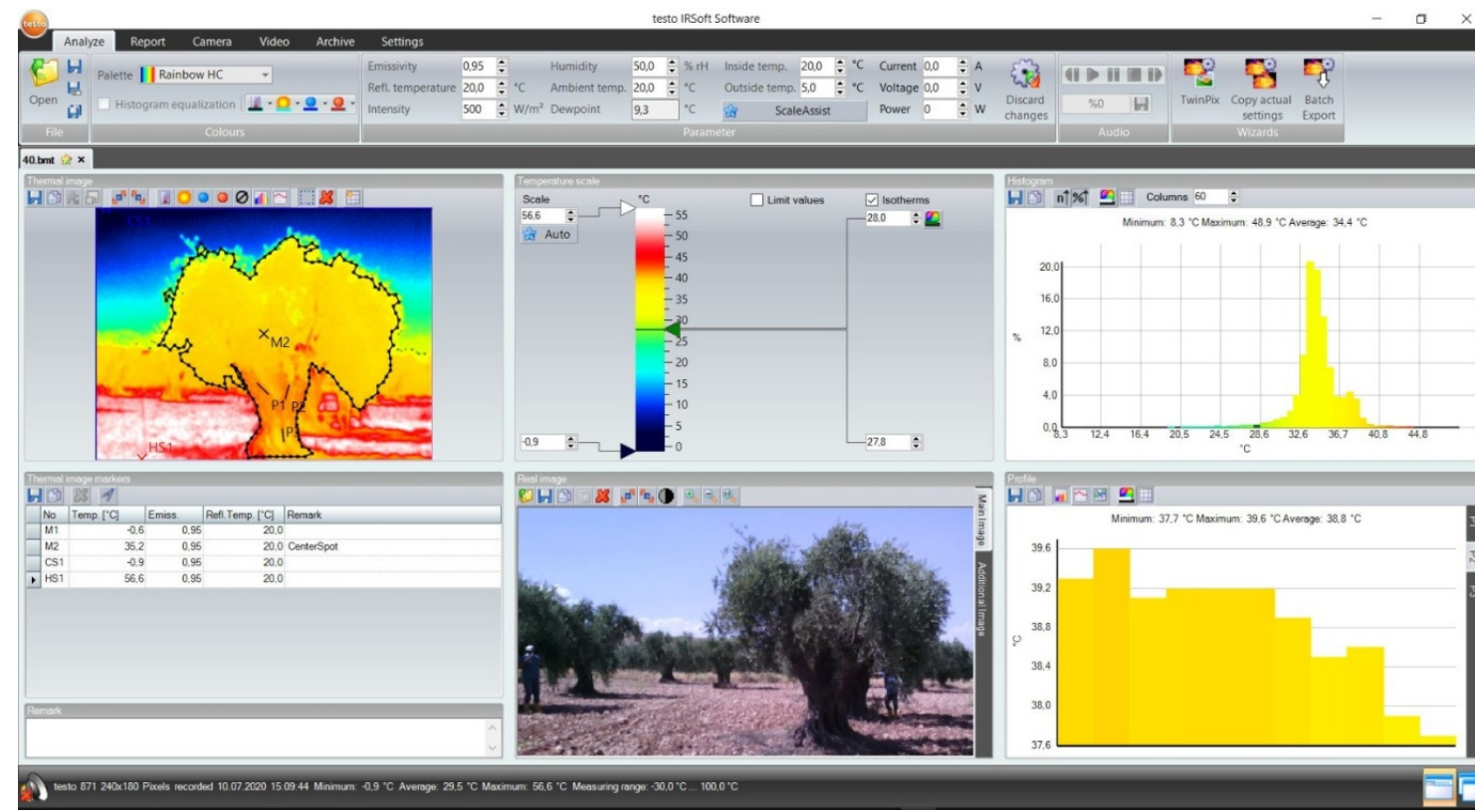

Figure 10. Rainbow scale olive tree thermal image analysis process with Testo IRSoft for the correct thermal detection

The most significant of the technique is that there is no negative impact on the health of the tree. Since there is no negative effect to any pieces of the tree, no defect, or no damage to the environment. Contingent upon the brand and model utilized, camera weights changes. In our study, the heaviness of the camera, which is utilized, alone is 510 grams. It is conceivable to watch warm images from the camera screen during shooting 
and get the ideal pictures. On account of this strategy, it tends to be resolved regardless of whether there are no indications of rot, repellent, and so forth happening in the inside of the trees, which can be seen remotely (Catena and Catena, 2008). Additionally, this strategy is conceivable to decide the periodicity arrangements that happen in the inside of the tree early and to follow their turn of events; essential assurance measures can likewise be taken promptly (Catena, 2003). Recently, the technique is known to be effectively used in trees up to $120 \mathrm{~cm}$ across.

Catena and Catena (2008) express that the most significant burden of the technique is that the utilized camera (even though it changes as indicated by its model) is very costly. Costs are rising altogether in cutting edge cameras. In any case, the strategy has a wide scope of usage area, for example, medication, industry, military applications, untamed life contemplates, and so on. In this manner, the price hindrance of the framework ought to be assessed along with the benefit of multi-faceted use. There is likewise the alternative to lease cameras for specific periods. The second most significant disadvantage is that the strategy must be utilized to recognize the presence of misfortune and which parts of the body are spread; it is preposterous to expect to decide the nature and reasons for the harm by this technique. In a stormy climate, thermography is not an accessible method when the tree surface is covered with water or sunbathed.

Data mining approach

For this approach, one abnormal olive tree was selected from different age, because each of the trees needs different treatment based on the different environmental effects and physiological properties of the olive trees, and 150 thermal data measurements were obtained from the normal trunk and 75 data were obtained from abnormal trunk parts. They were analysed by using the decision tree and random forest classification algorithms with the help of Knime software.

\section{Decision tree learning}

Decision tree learning is one of the most applied supervised learning algorithms among tree-based learning algorithms. Decision trees such as gradient boost tree and random forest, which are used in data science problems, are also significantly and widely used. Therefore, it is applied to the result of multi-class data. The algorithm divides the total data into learning and predicting database on software settings. According to the training (train) data set, the structure of the tree changes, and groupings are shaped accordingly.

Decision trees can perform operations on numeric or non-numeric values, based on classification labels on their statuses, estimating critical points from the average distribution of numerical data. According to the entropy values of these classes, after the alignment on the tree, these sequences are checked, and the desired values are progressed in the branches of this decision tree and it is reaching the conclusion.

Process in the decision tree, the goal is to get the most efficient result, often keeping the collected data short, and trying to make it understandable results by removing it the complexity as much as possible. Accordingly, three basic methods are used to make the decision tree more efficient and optimally available. First, labels in the classification problem are formulated and the entropy formula (D: the information used for classification) is applied according to the number of labels (Formula 1).

$$
\operatorname{Info}(D)=-\sum_{i=l}^{m} p_{i} \log _{2}\left(p_{i}\right)
$$

This algorithm aims to keep the generated data at a minimum depth, and the property is select and position to the top point within the tree. Entropy is the reason for the data and decision tree algorithm used in this study to classify the temperature at the top. Each of these classifications is calculated separately and each calculated class provides information for a property (Formula 2).

$$
\operatorname{Info}_{A}(D)=\sum_{j=1}^{v} \frac{\left|D_{j}\right|}{|D|} \times \operatorname{Info}\left(D_{j}\right)
$$


Each of these classifications is calculated separately and each calculated class provides information for a property. At the end of the calculation, the feature that provides the highest knowledge and efficiency according to the extraction process is branched downwards depending on other characteristics starting from the beginning of the tree, and accordingly, the most efficient classification of the tree is selected (Formula 3 ).

$$
\operatorname{Gain}(\mathrm{A})=\operatorname{Info}(\mathrm{D})-\operatorname{Info}_{A}(D)
$$

\section{Theory of random forest learning}

The random forest algorithm has emerged as a more stable running algorithm based on the CART algorithm used among decision trees. It is popularized among other methods of meta-learning because it creates multiple decision trees differently and produces fast and simple results. The random tree aims to teach each decision tree differently, either by the algorithm, it develops here, or the way it feeds the data, and allows trees to learn data differently. Therefore, there are more than one and different decision trees. The data set used by the decision tree algorithm for classification is divided into two (training-test) and the algorithm creates a model using training data. In the model that occurs, the success of the model on the problem is calculated by performing an application with test data. As a result, the random tree randomly throws each decision tree, and it makes a vote on trees, with the different models for decision trees and the average of the success of this model. The Gini index is calculated by the following equation to create a tree with random forest algorithm criteria (Formula 4) (Küçükönder et al., 2015).

$$
\operatorname{Info}_{A}(D)=\sum_{j=1}^{v} \frac{\left|D_{j}\right|}{|D|} \times \operatorname{Info}\left(D_{j}\right)
$$

\section{Knime application}

The application of these data mining-based classification algorithms done by using the KNIME Analytics Platform. It is designed for discovering the potential hidden in data, mining for fresh insights, or predicting new futures. Knime decision tree and random forest data mining algorithms can be seen in Figure 11.

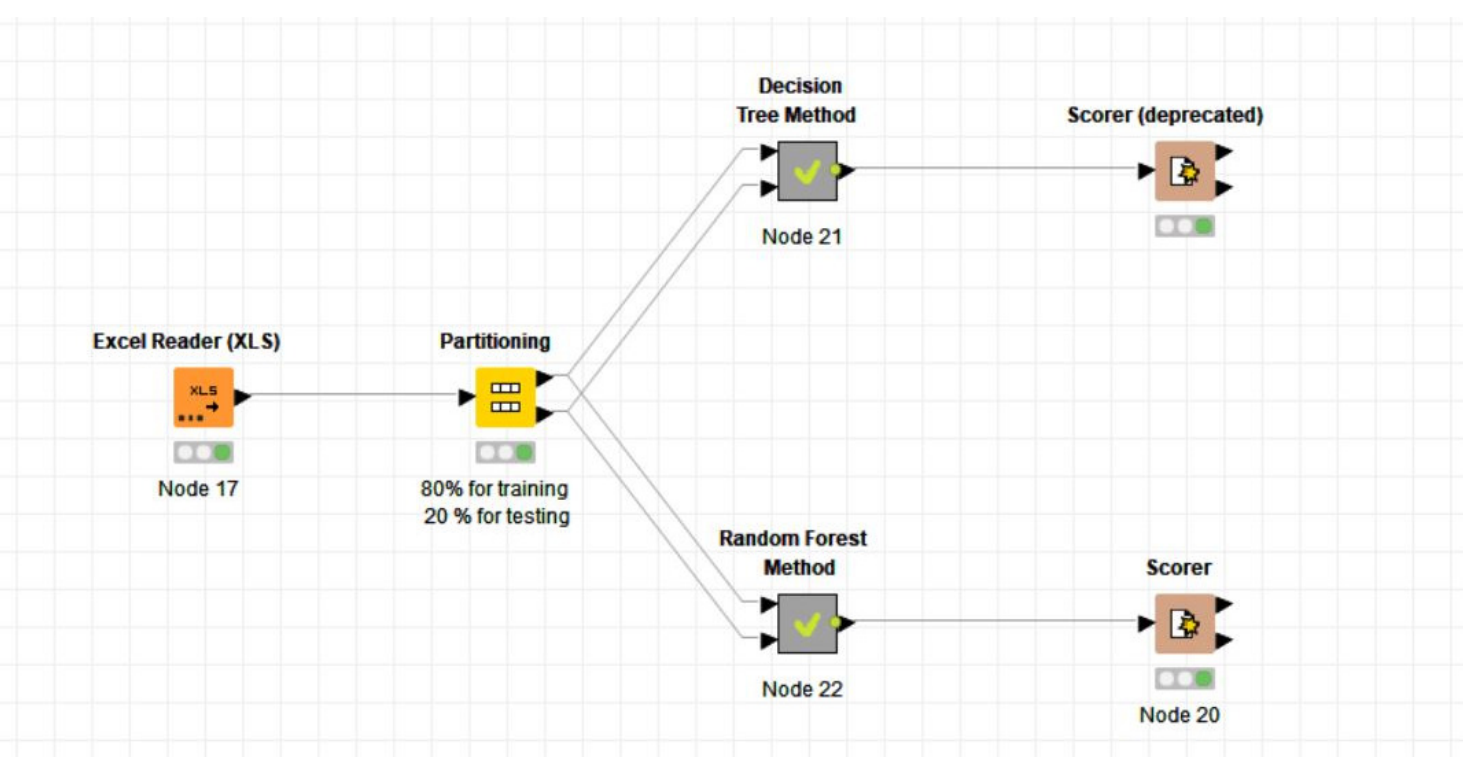

Figure 11. Knime decision tree and random forest data mining algorithms 


\section{Results}

Image processing-based dimension measurements and canopy volumes of 60 -years-old olive trees can be seen in Table 2. The olive trees have an average $0.89 \mathrm{~m}$ height from ground to canopy skirt, $2.41 \mathrm{~m}$ height to the point of maximum canopy diameter, $4.81 \mathrm{~m}$ overall canopy height above ground level, $4.70 \mathrm{~m}$ canopy diameter parallel to the row, and $56.44 \mathrm{~m}^{3}$ canopy volume.

Table 2. Image processing-based dimension measurements and canopy volumes of 60-years-old olive trees

\begin{tabular}{|c|c|c|c|c|c|}
\hline Tree No & $\mathrm{H}_{S}(\mathrm{~m})$ & $\mathrm{H}_{\mathrm{C}}(\mathrm{m})$ & $\mathrm{H}_{\mathrm{T}}(\mathrm{m})$ & $\mathrm{D}(\mathrm{m})$ & $\mathrm{PS}_{\mathrm{cv}}\left(\mathrm{m}^{3}\right)$ \\
\hline 1 & 1.14 & 2.78 & 5.12 & 4.74 & 56.44 \\
\hline 2 & 0.87 & 1.86 & 3.73 & 3.32 & 19.35 \\
\hline 3 & 0.66 & 2.28 & 4.62 & 4.68 & 54.67 \\
\hline 4 & 0.80 & 2.38 & 4.98 & 4.42 & 50.81 \\
\hline 5 & 0.78 & 2.31 & 4.47 & 5.41 & 68.24 \\
\hline 6 & 0.86 & 2.47 & 4.96 & 5.25 & 70.75 \\
\hline 7 & 0.57 & 2.49 & 5.28 & 4.93 & 72.12 \\
\hline 8 & 0.78 & 1.91 & 3.86 & 4.39 & 36.76 \\
\hline 9 & 1.20 & 2.30 & 4.87 & 5.31 & 62.27 \\
\hline 10 & 1.30 & 2.30 & 4.15 & 3.19 & 17.84 \\
\hline 11 & 0.69 & 2.15 & 4.57 & 4.72 & 53.75 \\
\hline 12 & 0.95 & 2.40 & 5.20 & 4.94 & 63.54 \\
\hline 13 & 0.73 & 2.23 & 4.51 & 4.90 & 56.92 \\
\hline 14 & 0.80 & 2.49 & 5.20 & 4.46 & 54.60 \\
\hline 15 & 0.87 & 2.79 & 4.94 & 4.20 & 46.43 \\
\hline 16 & 0.95 & 2.47 & 4.72 & 4.68 & 51.92 \\
\hline 17 & 0.92 & 2.85 & 5.42 & 5.43 & 84.33 \\
\hline 18 & 1.19 & 2.85 & 5.94 & 5.71 & 95.21 \\
\hline Avg $(\mathrm{m})$ & 0.89 & 2.41 & 4.81 & 4.70 & 56.44 \\
\hline
\end{tabular}

Also, image processing-based dimension measurements and canopy volumes of 400-years-old olive trees can be seen in Table 3 . According to the table, olive trees have an average $0.89 \mathrm{~m}$ height from ground to canopy skirt, $2.32 \mathrm{~m}$ height to the point of maximum canopy diameter, $4.76 \mathrm{~m}$ overall canopy height above ground level, $4.35 \mathrm{~m}$ canopy diameter parallel to the row, and $49.37 \mathrm{~m}^{3}$ canopy volume.

Table 3. Image processing-based dimension measurements and canopy volumes of 400-years-old olive trees

\begin{tabular}{|c|c|c|c|c|c|}
\hline Tree No & $\mathrm{H}_{\mathbf{S}}(\mathrm{m})$ & $\mathrm{H}_{\mathrm{C}}(\mathrm{m})$ & $\mathrm{H}_{\mathrm{T}}(\mathrm{m})$ & $\mathrm{D}(\mathrm{m})$ & $\mathrm{PS}_{\mathrm{cv}}\left(\mathrm{m}^{3}\right)$ \\
\hline 1 & 0.96 & 2.76 & 5.18 & 5.21 & 72.73 \\
\hline 2 & 0.97 & 2.72 & 5.21 & 5.60 & 83.95 \\
\hline 3 & 0.88 & 2.46 & 5.29 & 5.16 & 72.46 \\
\hline 4 & 0.94 & 2.75 & 5.94 & 4.81 & 71.50 \\
\hline 5 & 0.85 & 2.68 & 5.72 & 5.60 & 94.94 \\
\hline 6 & 0.65 & 1.83 & 4.24 & 4.14 & 37.49 \\
\hline 7 & 0.92 & 2.00 & 4.31 & 3.84 & 30.33 \\
\hline 8 & 0.94 & 2.40 & 4.08 & 3.28 & 21.79 \\
\hline 9 & 0.83 & 2.16 & 4.24 & 4.37 & 40.73 \\
\hline 10 & 0.58 & 3.02 & 6.55 & 5.63 & 119.27 \\
\hline 11 & 0.93 & 2.04 & 4.84 & 4.32 & 43.61 \\
\hline 12 & 0.83 & 1.96 & 4.01 & 3.34 & 21.86 \\
\hline 13 & 1.05 & 2.20 & 4.64 & 3.69 & 29.68 \\
\hline 14 & 0.8 & 2.05 & 4.12 & 3.78 & 29.50 \\
\hline
\end{tabular}


Beyaz A and Ozkaya MT (2021). Not Bot Horti Agrobo 49(1):12139

\begin{tabular}{|c|l|l|l|l|l|}
\hline 15 & 1.07 & 2.58 & 5.23 & 4.42 & 50.25 \\
\hline 16 & 0.82 & 2.21 & 4.75 & 4.58 & 50.77 \\
\hline 17 & 1.03 & 2.07 & 4.32 & 4.00 & 31.90 \\
\hline 18 & 0.88 & 2.08 & 3.98 & 3.21 & 19.95 \\
\hline 19 & 1.12 & 2.41 & 4.90 & 3.89 & 35.04 \\
\hline 20 & 0.75 & 2.06 & 4.20 & 3.82 & 31.35 \\
\hline 21 & 0.85 & 2.34 & 4.25 & 4.69 & 47.71 \\
\hline Avg (m) & 0.89 & 2.32 & 4.76 & 4.35 & 49.37 \\
\hline
\end{tabular}

At last, image processing-based dimension measurements and canopy volumes of 600-years-old olive trees can be seen in Table 4. According to the table, olive trees have an average $1.36 \mathrm{~m}$ height from ground to canopy skirt, $2.53 \mathrm{~m}$ height to the point of maximum canopy diameter, $4.47 \mathrm{~m}$ overall canopy height above ground level, $4.77 \mathrm{~m}$ canopy diameter parallel to the row, and $47.32 \mathrm{~m}^{3}$ canopy volume.

Table 4. Image processing-based dimension measurements and canopy volumes of 600-years-old olive trees

\begin{tabular}{|c|c|c|c|c|c|}
\hline Tree No & $\mathrm{H}_{S}(\mathrm{~m})$ & $\mathrm{H}_{\mathrm{C}}(\mathrm{m})$ & $\mathrm{H}_{\mathrm{T}}(\mathrm{m})$ & $\mathrm{D}(\mathrm{m})$ & $\mathrm{PS}_{\mathrm{cv}}\left(\mathrm{m}^{3}\right)$ \\
\hline 1 & 1.36 & 2.90 & 4.95 & 5.22 & 62.17 \\
\hline 2 & 1.55 & 3.16 & 5.13 & 5.40 & 66.92 \\
\hline 3 & 1.21 & 2.46 & 4.48 & 4.66 & 44.26 \\
\hline 4 & 1.32 & 2.00 & 3.45 & 3.28 & 13.91 \\
\hline 5 & 1.58 & 2.74 & 4.95 & 3.98 & 32.74 \\
\hline 6 & 0.99 & 2.38 & 4.89 & 4.62 & 51.33 \\
\hline 7 & 1.57 & 2.91 & 5.33 & 6.64 & 102.22 \\
\hline 8 & 0.75 & 2.00 & 4.00 & 5.14 & 53.58 \\
\hline 9 & 1.82 & 2.78 & 4.39 & 3.49 & 19.44 \\
\hline 10 & 1.22 & 2.34 & 3.72 & 4.01 & 25.75 \\
\hline 11 & 1.34 & 2.46 & 4.22 & 4.14 & 30.86 \\
\hline 12 & 1.40 & 2.58 & 5.01 & 5.23 & 60.12 \\
\hline 13 & 1.09 & 2.05 & 4.00 & 4.50 & 35.93 \\
\hline 14 & 1.38 & 2.31 & 3.75 & 3.74 & 20.75 \\
\hline 15 & 1.46 & 2.65 & 4.21 & 4.35 & 33.12 \\
\hline 16 & 1.34 & 2.33 & 3.80 & 3.65 & 20.60 \\
\hline 17 & 1.40 & 2.32 & 4.27 & 3.41 & 20.26 \\
\hline 18 & 1.10 & 2.21 & 2.87 & 4.64 & 26.20 \\
\hline 19 & 1.40 & 2.54 & 4.70 & 5.87 & 69.79 \\
\hline 20 & 1.45 & 2.72 & 5.59 & 5.65 & 79.77 \\
\hline 21 & 1.79 & 2.92 & 4.54 & 4.52 & 35.44 \\
\hline 22 & 1.27 & 2.31 & 4.32 & 4.71 & 41.45 \\
\hline 23 & 0.83 & 1.83 & 3.53 & 3.74 & 23.42 \\
\hline 24 & 1.16 & 2.39 & 4.65 & 4.13 & 36.64 \\
\hline 25 & 1.14 & 2.14 & 3.71 & 4.00 & 25.71 \\
\hline 26 & 1.56 & 3.00 & 4.80 & 4.13 & 35.35 \\
\hline 27 & 1.55 & 2.63 & 4.00 & 3.79 & 22.48 \\
\hline 28 & 1.40 & 2.53 & 4.35 & 4.31 & 34.17 \\
\hline 29 & 1.42 & 2.47 & 3.41 & 3.90 & 20.02 \\
\hline 30 & 1.47 & 2.45 & 4.30 & 5.95 & 61.51 \\
\hline 31 & 1.56 & 2.37 & 4.15 & 4.11 & 26.48 \\
\hline 32 & 1.55 & 3.09 & 5.49 & 5.56 & 76.20 \\
\hline 33 & 1.40 & 2.45 & 4.50 & 4.64 & 40.84 \\
\hline 34 & 1.38 & 2.63 & 4.50 & 4.16 & 33.92 \\
\hline
\end{tabular}




\begin{tabular}{|c|c|c|c|c|c|}
\hline 35 & 1.47 & 2.81 & 5.35 & 5.34 & 67.90 \\
\hline 36 & 1.53 & 2.73 & 4.73 & 7.00 & 97.44 \\
\hline 37 & 1.08 & 2.68 & 4.50 & 4.89 & 52.81 \\
\hline 38 & 1.60 & 3.27 & 5.87 & 5.60 & 83.78 \\
\hline 39 & 1.31 & 2.24 & 5.00 & 5.69 & 70.40 \\
\hline 40 & 1.89 & 2.90 & 4.40 & 4.40 & 30.55 \\
\hline 41 & 1.55 & 2.32 & 4.72 & 4.73 & 41.62 \\
\hline 42 & 1.50 & 2.65 & 5.25 & 6.82 & 105.28 \\
\hline 43 & 0.78 & 1.75 & 3.83 & 3.83 & 27.14 \\
\hline 44 & 1.19 & 2.58 & 4.36 & 4.94 & 49.36 \\
\hline 45 & 1.32 & 2.43 & 4.92 & 5.94 & 76.72 \\
\hline 46 & 1.49 & 2.68 & 4.13 & 4.80 & 39.01 \\
\hline 47 & 1.21 & 2.84 & 4.93 & 5.61 & 74.69 \\
\hline 48 & 1.27 & 2.54 & 5.03 & 5.82 & 77.91 \\
\hline 49 & 1.23 & 2.54 & 4.01 & 5.26 & 49.74 \\
\hline 50 & 1.15 & 2.46 & 4.50 & 4.80 & 48.29 \\
\hline Avg $(m)$ & 1.36 & 2.53 & 4.47 & 4.77 & 47.52 \\
\hline
\end{tabular}

According to table data, canopy volumes of the olive trees are decreasing parallel with the age increase. Because the dead branches are increasing with the age increase and they are pruning every season. On the contrary to this canopy decrease, leaf numbers are increasing in each branch of old trees.

Thermal analysis measurement results of 60, 400, 600-years-old olive trees in Figures 12 to 14 respectively. According to the data on figures, generally, isotherm temperatures (TI) are lower than olive tree temperatures (TT), and abnormality temperature (TA) values higher than olive tree temperature.

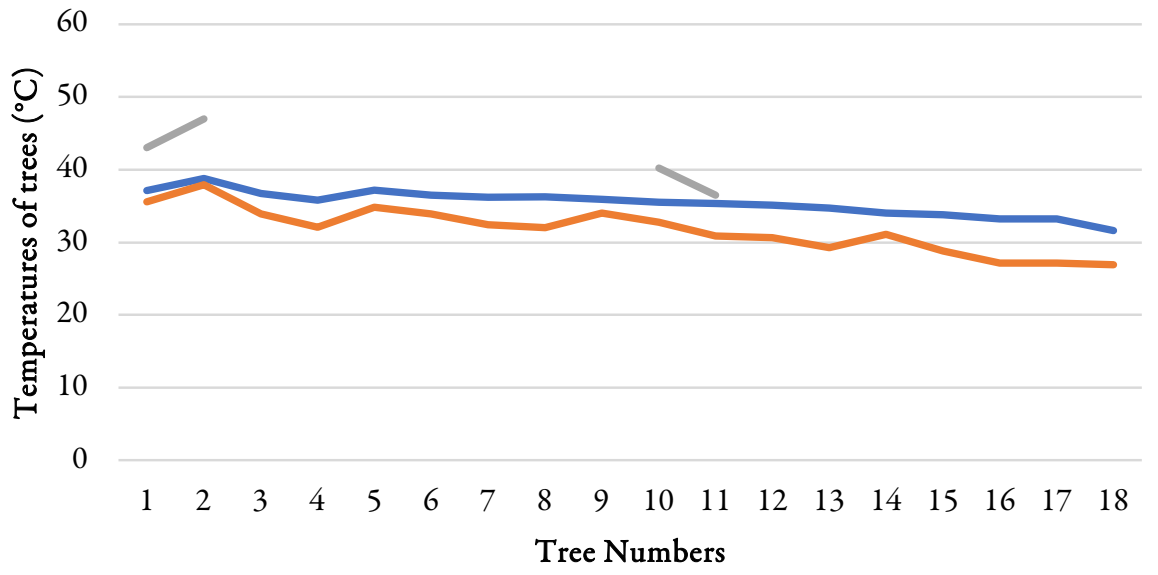

$\longrightarrow \mathrm{TT}(60 \mathrm{Age}) \longrightarrow \mathrm{TI}(60 \mathrm{Age}) \longrightarrow \mathrm{TA} 1(60 \mathrm{Age}) \quad \mathrm{TA} 2(60 \mathrm{Age})$

Figure 12. Thermal analysis measurement (TI: Isotherm temperatures, TT: Olive tree temperatures, TA: Abnormality temperature) results of 60 -years-old olive trees

Also, the data on Figure 12 for 60 -years-old olive trees, isotherm temperatures (Avg $31.73{ }^{\circ} \mathrm{C}$ ) are lower than olive tree temperatures $\left(\operatorname{Avg} 35.83^{\circ} \mathrm{C}\right.$ ), and first group abnormality temperature (Avg $41.67^{\circ} \mathrm{C}$ ), second group abnormality temperature $\left(\operatorname{Avg} 45.05^{\circ} \mathrm{C}\right)$ values higher than olive tree temperature. 


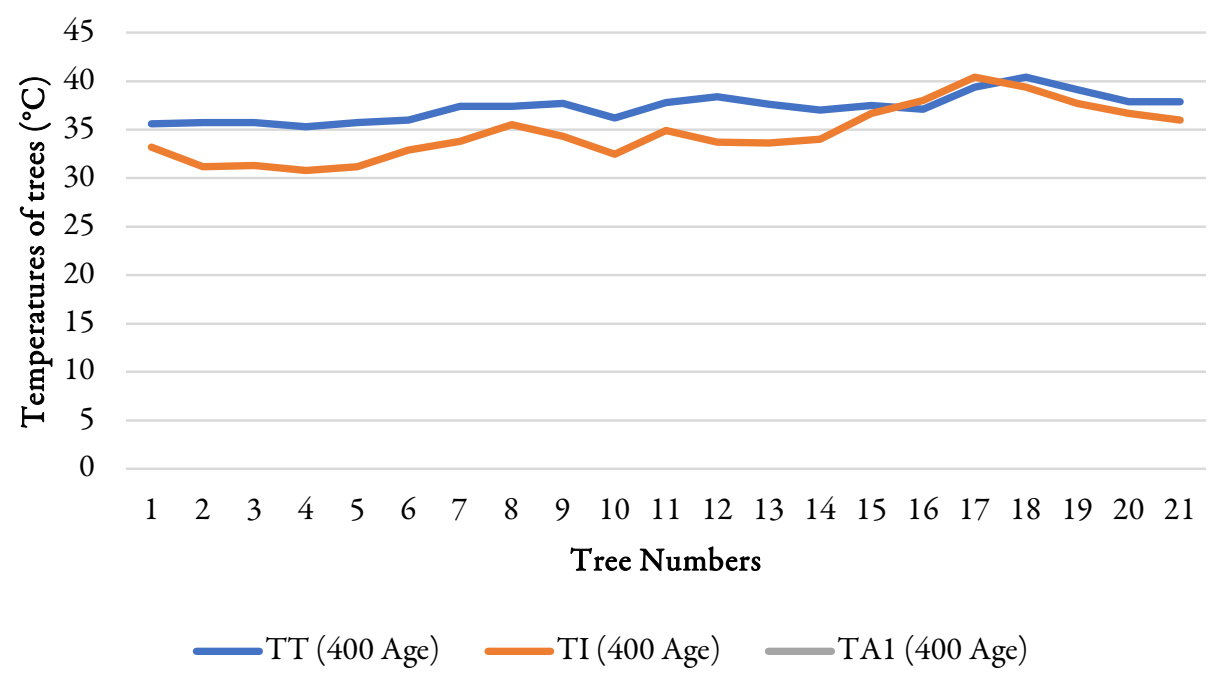

Figure 13. Thermal analysis measurement (TI: Isotherm temperatures, TT: Olive tree temperatures, TA: Abnormality temperature) results of 400-years-old olive trees

Additionally, according to the data in Figure 13 for 400-years-old olive trees, isotherm temperatures $\left(\right.$ Avg $34.65^{\circ} \mathrm{C}$ ) are lower than olive tree temperatures $\left(\operatorname{Avg} 37.27^{\circ} \mathrm{C}\right.$ ), and abnormality temperature (Avg $38.40^{\circ} \mathrm{C}$ ) values higher than olive tree temperature.

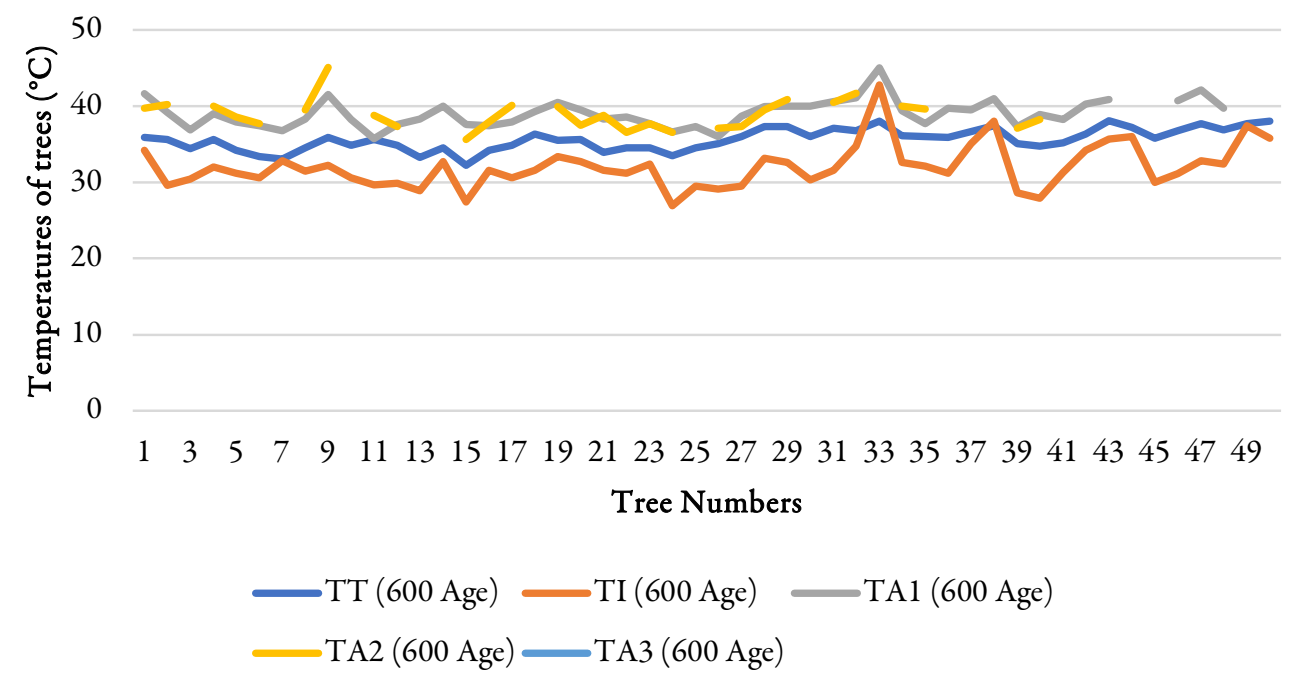

Figure 14. Thermal analysis measurement (TI: Isotherm temperatures, TT: Olive tree temperatures, TA: Abnormality temperature) results of 600-years-old olive trees

Similarly, according to the data in Figure 14 for 600 -years-old, isotherm temperatures (Avg $32.02{ }^{\circ} \mathrm{C}$ ) are lower than olive tree temperatures $\left(\operatorname{Avg} 35.60{ }^{\circ} \mathrm{C}\right)$, and first group abnormality temperature (Avg 39.08 $\left.{ }^{\circ} \mathrm{C}\right)$, second group abnormality temperature $\left(\operatorname{Avg} 38.99^{\circ} \mathrm{C}\right)$, third group abnormality temperature $(\operatorname{Avg} 41.00$ $\left.{ }^{\circ} \mathrm{C}\right)$ values higher than olive tree temperature. 
Beyaz A and Ozkaya MT (2021). Not Bot Horti Agrobo 49(1):12139

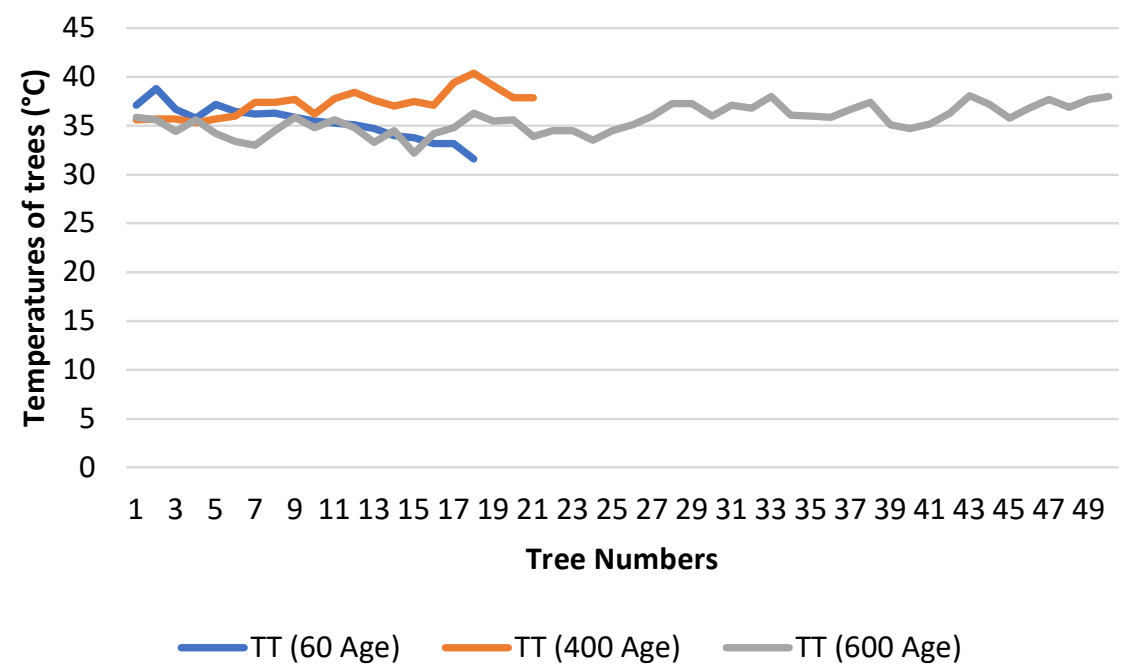

Figure 15. Temperatures of olive trees (TT) according to the ages

According to Figure 15. temperatures of olive trees parallel to the ages (olive tree temperatures for 60years-old avg $35.83^{\circ} \mathrm{C}$, olive tree temperatures for 400 -years-old avg $37.27^{\circ} \mathrm{C}$, olive tree temperatures for 600 years-old avg $35.60^{\circ} \mathrm{C}$ ) are not showing significant differences.

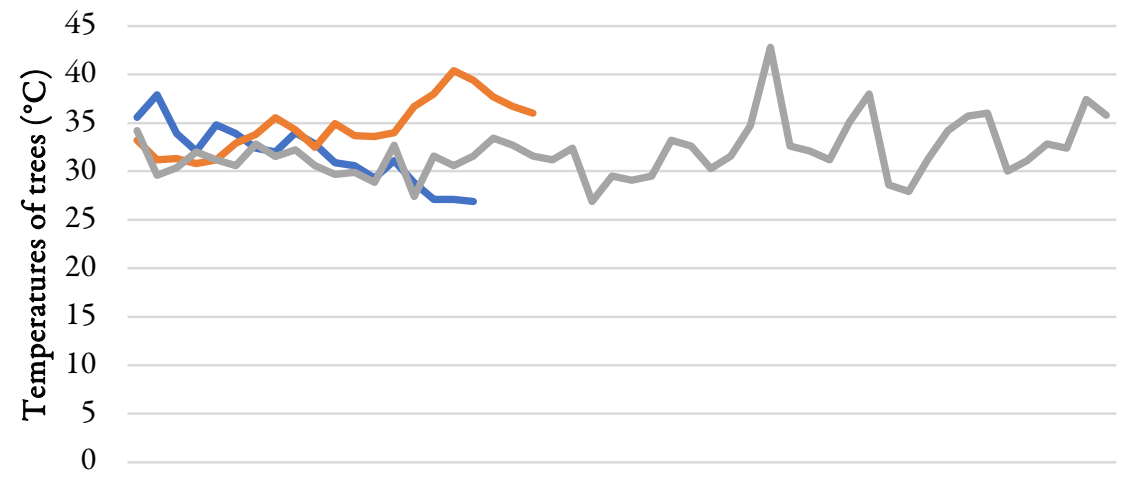

$1 \quad 357991113151719212325272931333537394143454749$

Tree Numbers

$\longrightarrow \mathrm{TI}(60$ Age $)=\mathrm{TI}(400 \mathrm{Age}) \quad \mathrm{TI}(600 \mathrm{Age})$

Figure 16. Isotherm temperatures of olive trees (TI) according to the ages

Also, isotherm temperature values of olive trees according to the ages (olive tree isotherm temperatures for 60 -years-old avg $31.73{ }^{\circ} \mathrm{C}$, olive tree isotherm temperatures for 400 -years-old avg $34.65{ }^{\circ} \mathrm{C}$, olive tree isotherm temperatures for 600 -years-old avg $32.02^{\circ} \mathrm{C}$ ) seen in Figure 16 are not showing significant changes. But isotherm regions of the olive trees are changing on the olive tree with the sunlight effect coming from environmental conditions (Figure 17). 

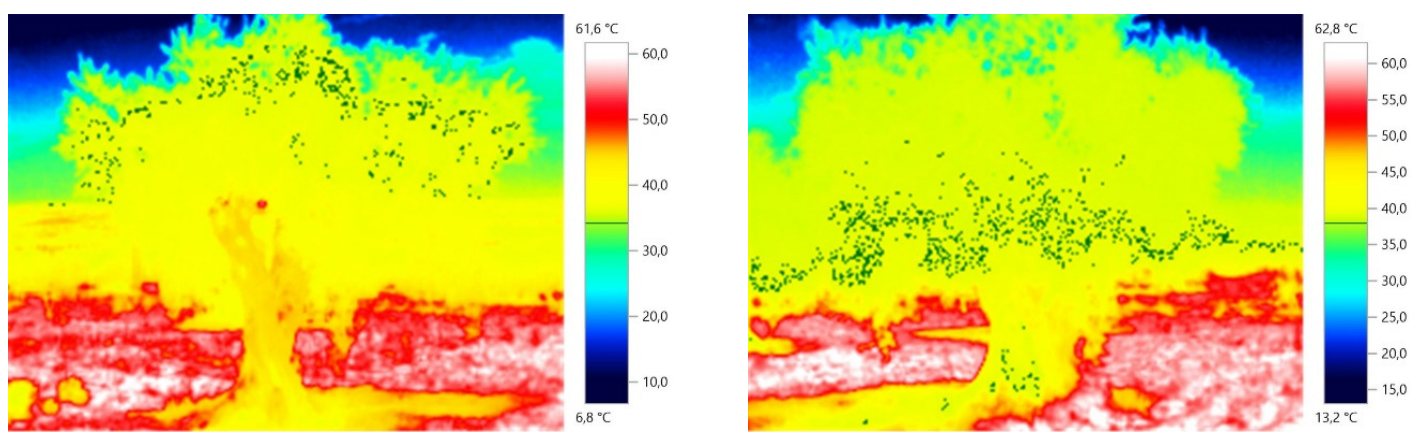

Figure 17. Isotherms of olive trees according to sunlight effect

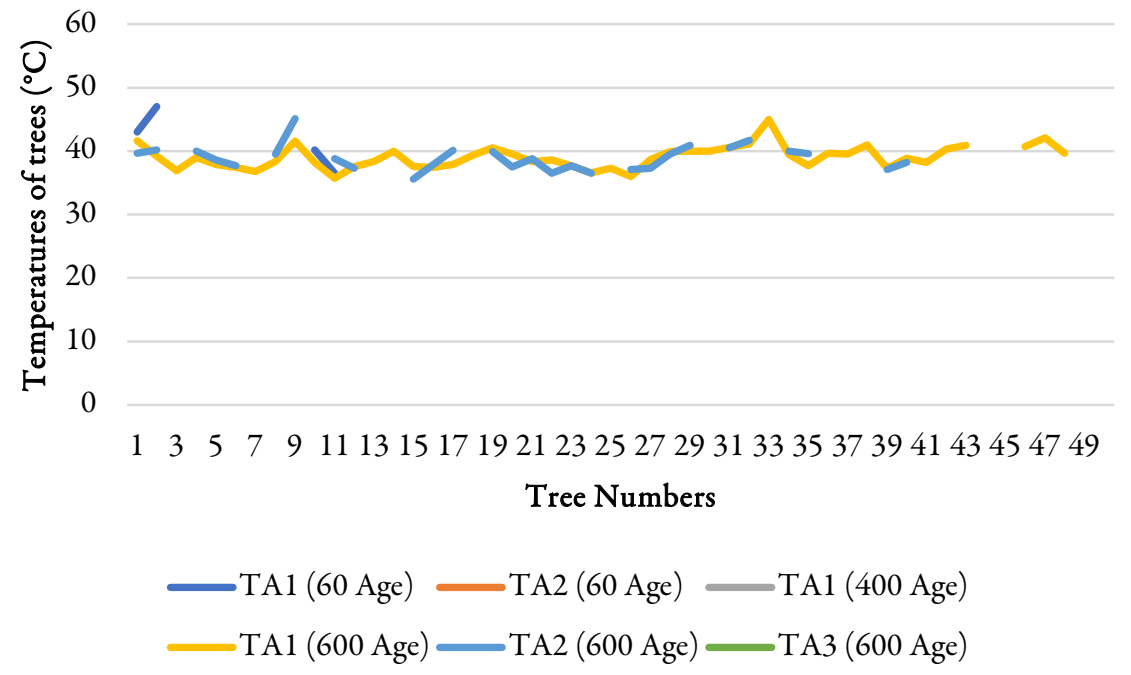

Figure 18. Abnormality temperatures (TA) of olive trees according to the ages

Also, according to Figure 18, thermal abnormalities temperatures (olive tree abnormality temperatures for 60-years-old changes between avg 41.67-45.05 ${ }^{\circ} \mathrm{C}$, olive tree abnormality temperatures for 400 -years-old avg $38.40{ }^{\circ} \mathrm{C}$, olive tree abnormality temperatures for 600-years-old changes between avg 39.08-38.99 ${ }^{\circ} \mathrm{C}$ ) are only showing the significant differences parallel at young 60 -years-old olive trees.

In addition to thermal average data, 60, 400, 600age olive trees 60-40 learning-prediction data rate (a), 70-30 learning-prediction data rate (b), 80-20 learning-prediction data rate (c) decision tree and random forest results can be seen in Figures 19-24. According to the thermal data on the olive tree trunk, normal and abnormal thermal difference range was found as $35.95^{\circ} \mathrm{C}$ at 60 -years-old tree, also it was found as $36.25^{\circ} \mathrm{C}$ at 400 -years-old tree and it was found as $38.25^{\circ} \mathrm{C}$ at 600 -years-old tree. 
Beyaz A and Ozkaya MT (2021). Not Bot Horti Agrobo 49(1):12139

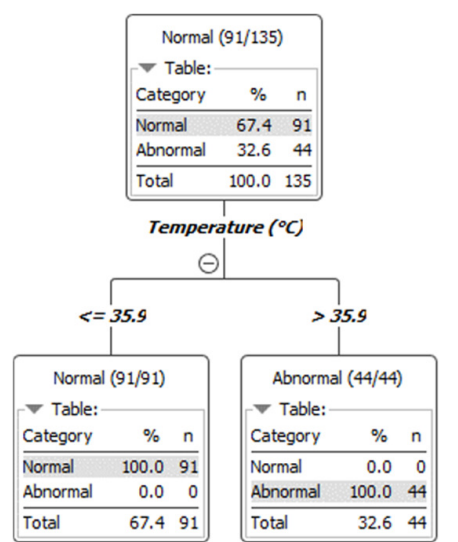

(a)

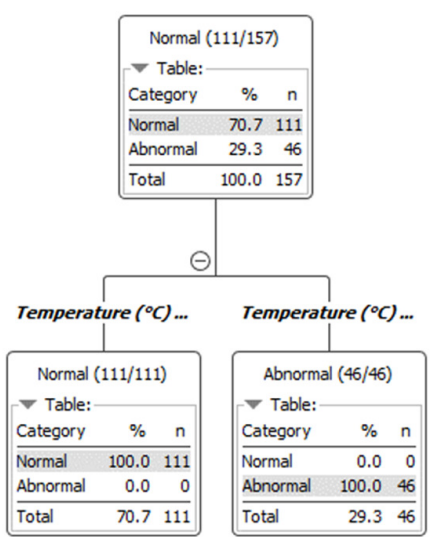

(b)

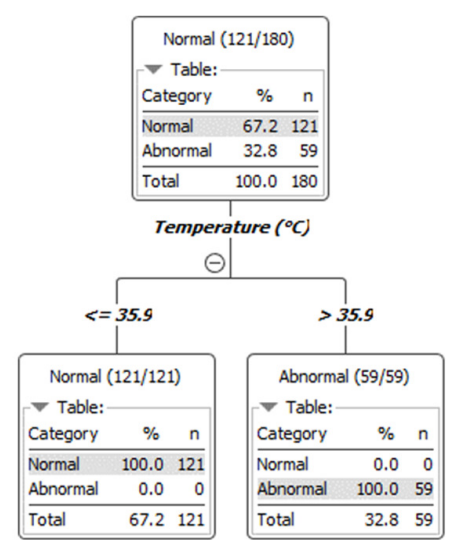

(c)

Figure 19. 60-years-old olive tree 60-40 learning-prediction data rate (a), 70-30 learning-prediction data rate (b), 80-20 learning-prediction data rate (c) decision tree results

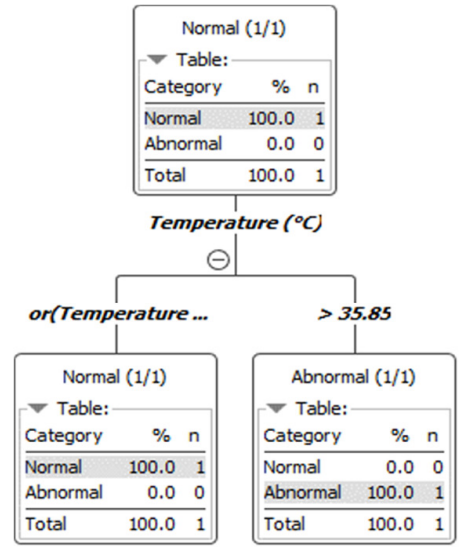

(a)

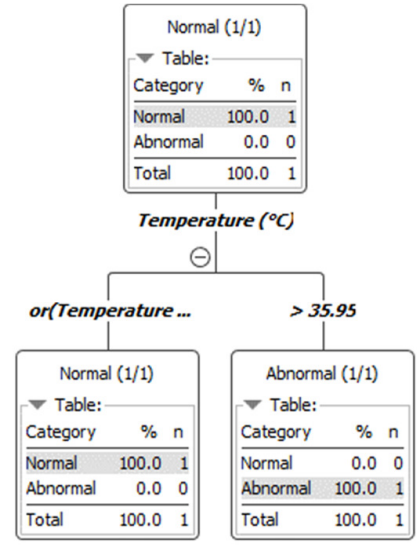

(b)

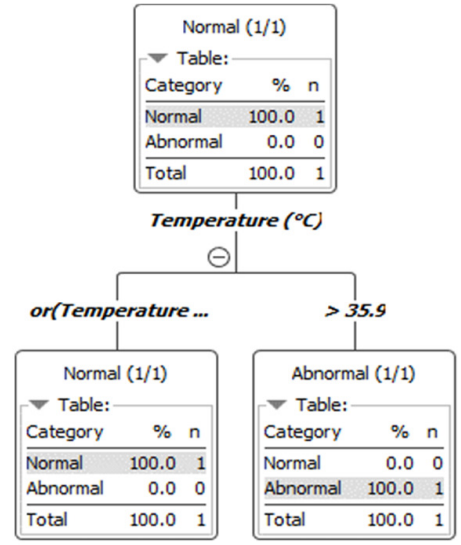

(c)

Figure 20. 60-years-old olive tree 60-40 learning-prediction data rate (a), 70-30 learning-prediction data rate (b), 80-20 learning-prediction data rate (c) random forest results

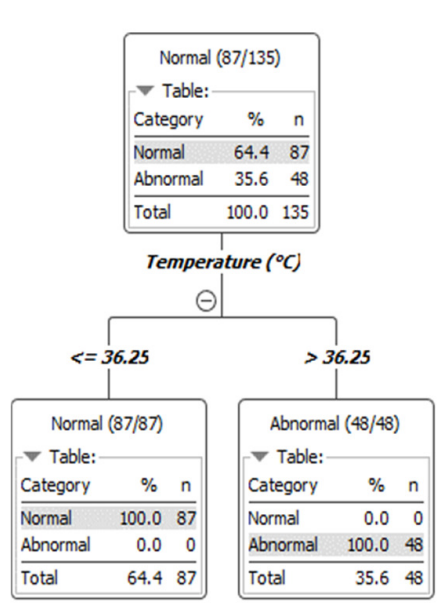

(a)

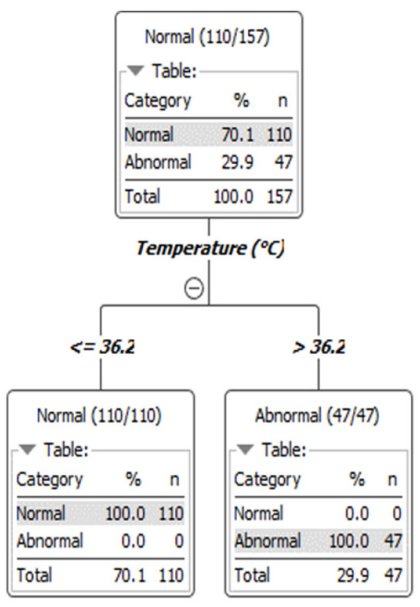

(b)

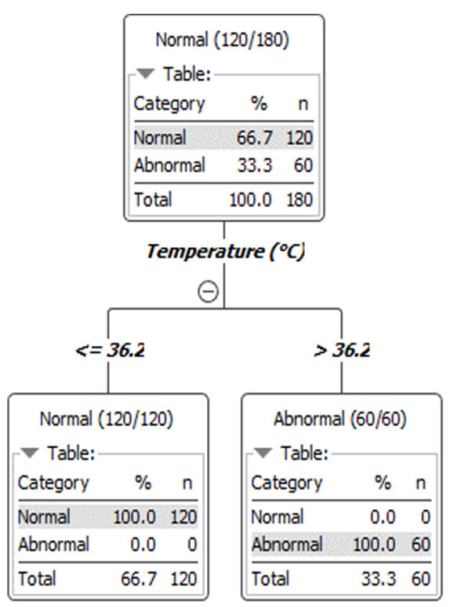

(c)

Figure 21. 400-years-old olive tree 60-40 learning-prediction data rate (a), 70-30 learning-prediction data rate (b), 80-20 learning-prediction data rate (c) decision tree results 
Beyaz A and Ozkaya MT (2021). Not Bot Horti Agrobo 49(1):12139

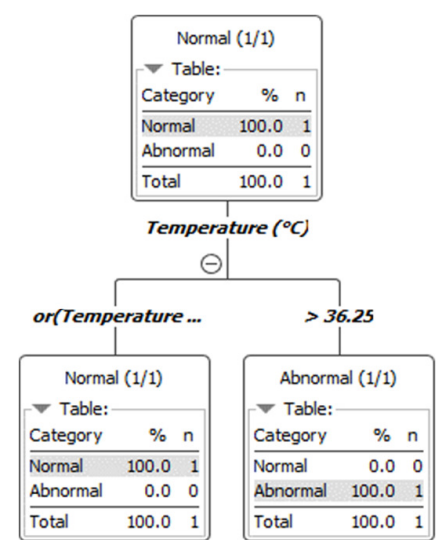

(a)

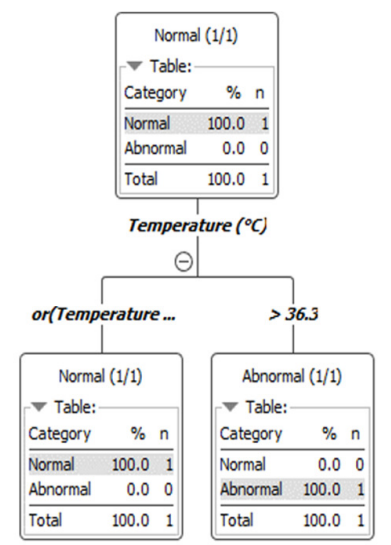

(b)

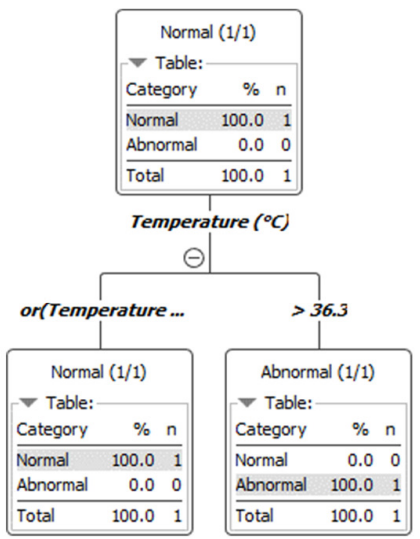

(c)

Figure 22. 400-years-old olive tree 60-40 learning-prediction data rate (a), 70-30 learning-prediction data rate (b), 80-20 learning-prediction data rate (c) random forest results

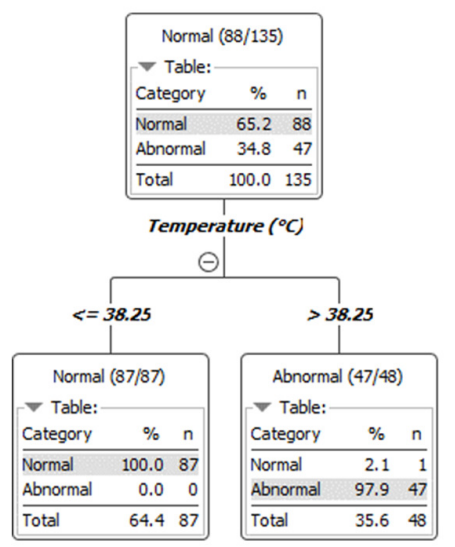

(a)

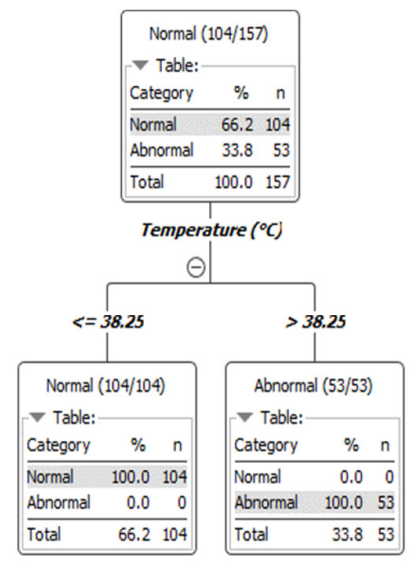

(b)

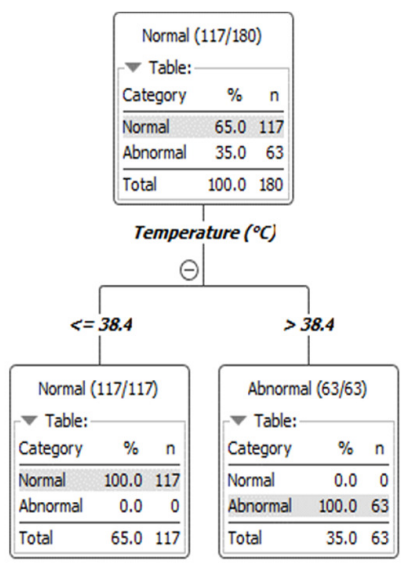

(c)

Figure 23. 600-years-old olive tree 60-40 learning-prediction data rate (a), 70-30 learning-prediction data rate (b), 80-20 learning-prediction data rate (c) decision tree results

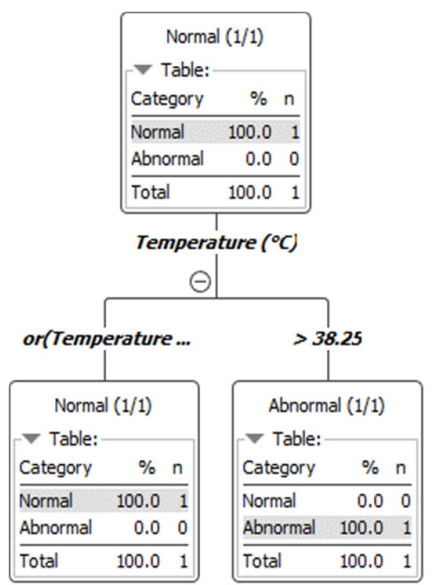

(a)

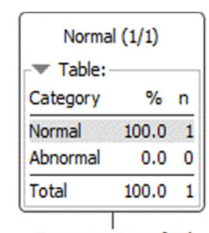

Temperature $\left({ }^{\circ} \mathrm{C}\right.$
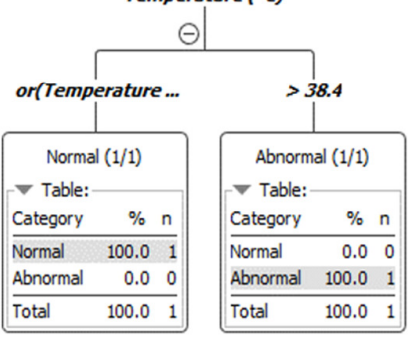

(b)

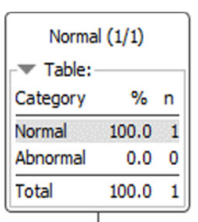

Temperature $\left({ }^{\circ} \mathrm{C}\right)$

$\ominus$

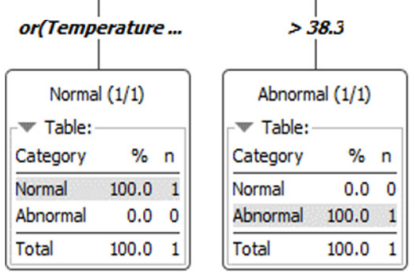

(c)

Figure 24. 600-years-old olive tree 60-40 learning-prediction data rate (a), 70-30 learning-prediction data rate (b), 80-20 learning-prediction data rate (c) random forest results 
Also, the olive tree decision tree and random forest accuracy results at different learning-prediction data rates can be seen in Table 5 .

Table 5. Olive tree decision tree and random forest accuracy results at different learning-prediction data rates

\begin{tabular}{|c|c|c|c|c|c|c|}
\hline & \multicolumn{2}{|c|}{60 years-old } & \multicolumn{2}{c|}{400 years-old } & \multicolumn{2}{c|}{600 years-old } \\
\hline $\begin{array}{c}\text { Learning- } \\
\text { prediction data } \\
\text { rate }\end{array}$ & $\begin{array}{c}\text { Decision tree } \\
(\%)\end{array}$ & $\begin{array}{c}\text { Random forest } \\
(\%)\end{array}$ & $\begin{array}{c}\text { Decision tree } \\
(\%)\end{array}$ & $\begin{array}{c}\text { Random forest } \\
(\%)\end{array}$ & $\begin{array}{c}\text { Decision tree } \\
(\%)\end{array}$ & $\begin{array}{c}\text { Random forest } \\
(\%)\end{array}$ \\
\hline $60-40$ & 100 & 100 & 100 & 100 & 98.88 & 98.88 \\
\hline $70-30$ & 100 & 100 & 100 & 100 & 97.05 & 97.05 \\
\hline $80-20$ & 100 & 100 & 100 & 100 & 97.77 & 97.77 \\
\hline
\end{tabular}

Therefore, even though the work on the utilization of the technique for thermography in olive trees giving data about abnormalities in the insides with no signs considered, and empowering the follow-up of these imperfections in the later stages, the important security measures for the tree can be taken. The most significant drawback of this strategy is that the cost is high. Even though the cost of a device is high, the use of this method has different advantages. With the thermography technique, it is just conceivable to decide the presence of the harm and which parts of the body are spreading. This strategy is a non-dangerous and viable technique that permits just the nearness and size of harm in olive trees to recognize and screen its turn of events.

\section{Conclusions}

With the study, an alternative application to classical tree health applications was made. In this way, it has been revealed that the application can be used actively for olive trees and different tree species. In various orchards consisting of different tree species, it is possible to make similar analyzes on the tree health in a fast and non-contact way without damaging the tree trunk.

\section{Authors' Contributions}

AB: Data curation, formal analysis, methodology, software, supervision, visualization, writing - original draft, writing - review and editing; MTO: Resources, investigation, validation.

Both authors read and approved the final manuscript.

\section{Acknowledgements}

This research received no specific grant from any funding agency in the public, commercial, or not-forprofit sectors.

\section{Conflict of Interests}

The authors declare that there are no conflicts of interest related to this article. 


\section{References}

Albrigo LG, Anderson CA, Edwards GJ (1975). Yield estimation of 'Valencia' orange research plots and groves. In: Proceedings Florida State Horticulture Society 88:44-49.

Bethge K, Mattheck C, Hunger E (1996). Equipment for detection and evaluation of incipient decay in trees. Arboricultural Journal 20:13-37. https://doi.org/10.1080/03071375.1996.9747095

Catena A (2003). Thermography reveals hidden tree decay. Arboricultural Journal 27:27-42. https://doi.org/10.1080/03071375.2003.9747360

Catena A, Catena G (2008). Overview of thermal imaging for tree assessment. Arboricultural Journal 30:259- 270. https://doi.org/10.1080/03071375.2008.9747505

Catena G, Catalano M, Palla L (1990). Thermal infrared detection of cavities in trees. European Journal of Forest Pathology 20:201-210. https://doi.org/10.1111/j.1439-0329.1990.tb01131.x

Deflorio G, Siegfried F, Schwarze FWMR (2008). Detection of incipient decay in tree stems with sonic tomography after wounding and fungal inoculation. Wood Science and Technology 42:117-132. https://doi.org/10.1007/s00226-007-0159-0

Dolwin J (1996). Evaluation of internal defects in trees and their legal implications. Arboricultural Journal 20:173-178. https://doi.org/10.1080/03071375.1996.9747112

Habermehl A, Ridder HW (1995). Computerised tomographic investigations of street and park trees. Arboricultural Journal 19:419-437. https://doi.org/10.1080/03071375.1995.9747089

Kubus M (2009). The evaluation of using resistograph when specifying the health condition of a monumental tree. Notulae Botanicae Horti Agrobotanici Cluj-Napoca 37(1):157-164. https://doi.org/10.15835/nbha3713112

Küçükönder H, Vursavuş KK, Üçkardeş F (2015). Determining the effect of some mechanical properties on color maturity of tomato with $\mathrm{k}$-star, random forest and decision tree (C4. 5) classification algorithms. Turkish Journal of Agriculture-Food Science and Technology 3(5):300-306. https://doi.org/10.24925/turjaf.v3i5.300306.261

Mattheck C, Breloer H (1994). Field guide for visual tree assessment (vta). Arboricultural Journal 18:1-23. https://doi.org/10.1080/03071375.1994.9746995

Roth DJ, Bodis JR, Bishop C (1997). Thermographic imaging for high-temperature composite materials- a defect detection study. Research in Nondestructive Evaluation 9:147-169. https://doi.org/10.1007/PL00003895

Sandoz JL (1999). Standing tree quality assessments using ultrasound. Acta Horticulturae 496:269-278. https://doi.org/10.17660/ActaHortic.1999.496.34
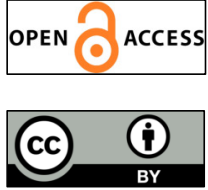

The journal offers free, immediate, and unrestricted access to peer-reviewed research and scholarly work. Users are allowed to read, download, copy, distribute, print, search, or link to the full texts of the articles, or use them for any other lawful purpose, without asking prior permission from the publisher or the author.

License - Articles published in Notulae Botanicae Horti Agrobotanici Cluj-Napoca are Open-Access, distributed under the terms and conditions of the Creative Commons Attribution (CC BY 4.0) License. (c) Articles by the authors; UASVM, Cluj-Napoca, Romania. The journal allows the author(s) to hold the copyright/to retain publishing rights without restriction. 